\title{
NOSOLOGICAL ENTITIES?
}

\section{"Paratrigeminal" paralysis of the oculopupillary sympathetic system}

\section{P J Goadsby}

Raeder described five patients with mixed features of trigeminal nerve pathology and oculosympathetic impairment, with or without other cranial nerve lesions. This constellation of clinical features drew the original author's attention to the paratrigeminal region as a likely site for the causative lesion in this syndrome. An analysis of the anatomy of the oculosympathetic innervation supports the view that a restricted lesion in the middle cranial fossa might cause the syndrome of trigeminal nerve involvement, neuralgic pain or sensory change, with ptosis or miosis, or both, but no anhidrosis. Such a paratrigeminal oculosympathetic syndrome (POSS) usefully reminds clinicians to pursue vigorously possible lesions of the middle cranial fossa with careful, and possibly repeated, imaging studies. Attaching the eponym Raeder's syndrome or Raeder's paratrigeminal neuralgia to this syndrome adds nothing valuable to the anatomical description (POSS), which might be preferred for clarity.

Correspondence to: Professor P J Goadsby, Institute of Neurology, Queen Square, London WCIN 3BG, UK peterg@ion.ucl.ac.uk

Received 11 September 2001

In revised form

1 November 2001

Accepted

8 November 2001 n 1924 Raeder $^{1}$ wrote a classic clinicalanatomical colocalisation paper that described five patients, one of whom had been reported in 1918. The patients had two key features: involvement of the trigeminal nerve and the oculosympathetic nerves. He sought to differentiate the restricted oculosympathetic findings from the classic Horner's syndrome: cervical sympathetic dysfunction characterised by ptosis, miosis, anhidrosis and enophthalmos. Since that time various terms have been employed, meanings defined, and classifications developed..$^{23}$ It is against this background that one ventures into the Coliseum that is the history of medicine to play out the academic battle. An eponym is useful if it conveys a very clear meaning, or perhaps acknowledges some contribution that was so pivotal as to provide insight well beyond the describer's demise. Raeder made an interesting clinical observation that pointed out the likely localisation of a lesion adjacent to the trigeminal nerve in the middle cranial fossa. In the era before cranial imaging this was a wonderful piece of neurology; in the modern era the eponym is much less useful. Solomon and Lustig ${ }^{4}$ recently set out the clinical cases that in many respects have illustrated the trigeminosympathetic anatomy of the carotid artery, concluding that the use of the term Raeder's paratrigeminal neuralgia had become corrupted to the point of being useless by careless attribution of cases that did not respect the anatomy. Conditions such as carotid disease, particularly dissection, may give rise to pain and a Horner's syndrome, ${ }^{3}$ and cluster headache may lead to oculosympathetic loss and impaired sympathetic facial sweating ${ }^{5}$ In both situations forehead sweating may be impaired. I will set out the relevant anatomy of the paratrigeminal region, then review Raeder's patients, and finally make some suggestions for the postimaging era based on an anatomical/pathophysiological designation for such patients.

\section{ANATOMY}

The key anatomical feature to be understood for Raeder's syndrome is the relation between the trigeminal nerve and the oculopupillary sympathetic fibres. The trigeminal nerve lies in the middle cranial fossa and in close proximity, paratrigeminally as Monrad-Krohn suggested, there are other cranial nerves. Most particularly for a short course the fibres that will innervate the levator palpebrae superioris, specifically Müller's muscle, and the pupilodilator fibres without the sudomotor fibres for the forehead. Therein is the anatomical lesson of Raeder.

\section{Cranial sympathetic innervation}

The sympathetic outflow ultimately arises in the hypothalamus and can be modulated by brain stem neurons. Preganglionic fibres arise from neurons in the lateral column of grey matter of the thoracic and upper two to three lumbar segments. The fibres emerge through the ventral roots of the corresponding spinal roots, passing into the spinal nerve trunks and their ventral rami. The fibres leave the ventral rami in the white rami communicantes to synapse in the corresponding ganglion or, in the circumstance of interest for the cervical sympathetic ganglia, to ascend before synapsing ${ }^{7}$ The sympathetic ganglia give rise to non-myelinated postganglionic fibres, which, for the head, arise as the internal carotid nerve from the superior cervical ganglion, which is, in effect, the rostralmost section of the sympathetic trunk. The cervical sympathetic ganglia destined to innervate the eye derive their input from the upper thoracic ( $\mathrm{Tl}$ ) sympathetic white rami communicantes.

\section{Oculosympathetic innervation}

The internal carotid nerve ascends with the internal carotid artery dividing into medial and lateral branches in the bony carotid canal, and forming a plexus known as the carotid plexus. The medial plexus communicates with the trigeminal ganglion and abducens nerve, and the lateral plexus 
Table 1 Raeder's cases

\begin{tabular}{|c|c|c|c|c|c|c|}
\hline \multirow[b]{2}{*}{ Patient (age, sex: pathology) } & \multicolumn{2}{|c|}{ Trigeminal sensory } & \multicolumn{3}{|c|}{ Oculosympathetic } & \multirow[b]{2}{*}{ Other cranial nerves } \\
\hline & Paint & Sensory change & Ptosis & Miosis & Anhidrosis & \\
\hline 18, male: parasellar endothelioma & + & - & + & + & - & $\begin{array}{l}\text { Trigeminal motor loss } \\
\text { Intermittent diplopia } \\
\text { Cranial parasympathetic activation }\end{array}$ \\
\hline 65 , male: not described & $+(*)$ & $+(\mathrm{V} 1$ loss $)$ & + & + & - & Diplopia \\
\hline 48 , male: run over by a car & ? & + (hypaesthesia) & + & + & ? & Paracentral scotoma \\
\hline 28, male: not described & $+\left({ }^{*}\right)$ & - & + & + & - & None \\
\hline 48 , male: injured by runaway horse & ? & $+(\mathrm{V} 1-\mathrm{V} 3$ loss $)$ & - & + & - & $\begin{array}{l}\text { Trigeminal motor loss } \\
\text { Hearing impaired } \\
\text { Reduced visual acuity }\end{array}$ \\
\hline
\end{tabular}

†Although often described as a neuralgia only the patients marked * had clear neuralgia.

? Indicates data not described in case.

communicates with the oculomotor, trochlear, ophthalmic, and abducens nerves, as well as the ciliary ganglion. The dilator pupillae fibres travel with either of the ophthalmic artery, nasociliary or long ciliary nerves, and those for levator palpebrae superioris travel with the oculomotor nerve.

\section{Sympathetic control of facial flushing}

The cervical sympathetic pathway is responsible for facial sweating and flushing, among other roles. The oculosympathetic and facial flushing roles seem well differentiated functionally given that central lesions have been reported in which the facial sweating is spared in the presence of an oculosympathetic lesion. ${ }^{8}$ Indeed whereas oculosympathetic fibres arise from $\mathrm{Tl}$ those for sudomotor function arise at lower levels; certainly at T2/3. ${ }^{9}$ Sudomotor fibres destined for the forehead traverse the internal carotid plexus, whereas those for the remainder of the face traverse the external carotid plexus, excepting those for the cheek, which may take either route ${ }^{10}$ Sudomotor fibres destined for the forehead join the ophthalmic nerve in the region of the cavernous sinus reaching the skin through the supraorbital nerve ${ }^{11}$ Sweating of the forehead is, therefore, normally mediated by fibres that exit the internal carotid plexus relatively laterally when compared with the oculosympathetic fibres. It must be borne in mind that parasympathetic neurons may reinnervate the sweat glands, ${ }^{8}$ so that intact sweating may not necessarily imply sympathetic sudomotor integrity.

\section{Trigeminal nerve and oculosympathetic outflow}

As the internal carotid artery passes from being inferior to the trigeminal ganglion and oculomotor nerve, and before it lies medial to the anterior clinoid process, it must distribute from the lateral internal carotid plexus the fibres for the dilator pupillae and levator palpebrae superioris; the sympathetic fibres destined for the trigeminal ganglion being delivered from the medial plexus before that point, as described above. Thus a lesion restricted to the middle cranial fossa medial to the trigeminal ganglion and effectively lateral to the anterior clinoid, would produce trigeminal pain by direct irritation of the anteromedial ganglion or initial section of the ophthalmic division, and could interrupt oculosympathetic outflow. There would be no expected effect on facial sweating because the sudomotor fibres have exited before this point. Thus a paratrigeminal oculosympathetic syndrome arises.

\section{RAEDER'S PARATRIGEMINAL SYNDROME}

Set against the anatomy it is appriopriate to consider Raeder's patients. Table 1 summarises the patients by dividing up the clinical symptoms and signs to highlight the trigeminal and oculosympathetic involvement, as well as other relevant clinical features. Several features emerge from such an analysis.

\section{Trigeminal involvement}

Considering three possible types of trigeminal involvementpain, sensory change and motor signs-what is constant in Raeder's patients? Only three patients had pain and only two had neuralgia. Thus the term Raeder's paratrigeminal neuralgia is fanciful. Three patients had sensory change; one patient had pantrigeminal loss indicating that the lesion had moved lateral to the unique paratrigeminal region, and similarly patient 1 had motor loss indicating a more extensive lesion.

\section{Oculosympathetic loss}

All five of Raeder's patients had miosis, and four of five had ptosis. Four of five also had normal sudomotor function. Thus oculosympathetic loss which must be peripheral was demonstrated but without anihydrosis.

\section{Other signs}

Four out of five of the original patients had other cranial nerves involved. It is interesting that one had cranial parasympathetic activation, most likely simply as a result of pain and activation of the trigeminal-autonomic reflex ${ }^{12}$

\section{Status of Raeder's patients}

An analysis of Raeder's patients demonstrates several issues. It is notable that only two of the patients had neuralgia and two had lesions not restricted to the paratrigeminal region. Thus perhaps one patient at most, patient 4 , really illustrated in a pure fashion the anatomical construct that Raeder seemed to illustrate. An analysis of the patients and the relevant anatomy suggests that Raeder's paratrigeminal neuralgia might usefully be dropped from the textbooks with no substantive loss as the patients described did not really, perhaps save one, fulfil the anatomical requirements strictly.

\section{AN ANATOMICAL APPROACH: PARATRIGEMINAL OCULOSYMPATHETIC SYNDROME}

How might one usefully draw on the lesson that Raeder sought to teach, essentially one of functional anatomy, and make a useful clinical rule? It could be suggested that Raeder made a first, and very creditable, attempt to describe a clinically useful syndrome based on the relevant anatomy (fig 1). Patients with oculosympathetic loss, miosis or ptosis, or both, with normal forehead sweating, and evidence of trigeminal involvement, either sensory change or neuralgic pain, are highly likely to have a lesion in the middle cranial fossa that is medial to the trigeminal ganglion (paratrigeminal). The anatomy of this syndrome is clear with dissociation 


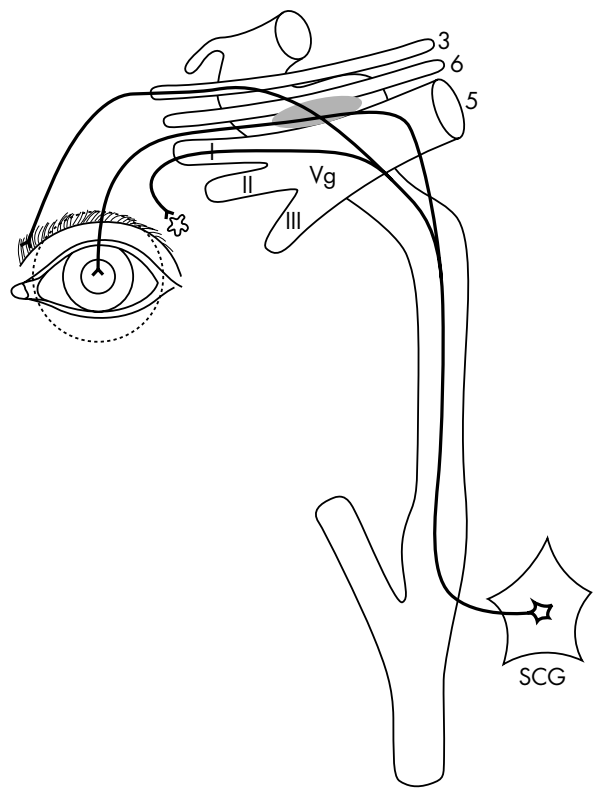

Figure 1 Drawing of the anatomy of the paratrigeminal oculosympathetic syndrome. Sympathetic fibres from the superior cervical ganglion (SCG) travel with the internal carotid artery in the neck, branching to innervate the sweat glands, levator palpebrae superioris (specifically Müller's muscle), and the pupilodilator fibres. The pupilodilator fibres travel near the ophthalmic portion of the trigeminal nerve, so that in this paratrigeminal region (grey shade) lesions produce the classic syndrome. 3, oculomotor nerve; 4, trochlear nerve; 5, trigeminal nerve; Vg, trigeminal ganglion, with first (I), second (II), and third (III) branches.

of the oculosympathetic outflow from forehead sweating in the middle cranial fossa; the only caveat being that if there is parasympathetic innervation of sympathetically dennervated sweat glands, as seen in cluster headache, ${ }^{8}$ then the sweating in Raeder's patients would be pathological and much of the argument would be lost. Given that Raeder was unaware of this and, therefore, could not have tested for it, the patients do not provide absolute evidence for his argument. Perhaps the name of the syndrome should simply reflect the anatomyparatrigeminal oculosympathetic syndrome-and thus fulfil the useful role of teaching. One might suggest that the term Raeder's paratrigeminal neuralgia is inaccurate, and Raeder's (paratrigeminal) syndrome does not teach the essential lesson in its name. Certainly, the unique combination of symptoms and signs should trigger an exhaustive search for a lesion with MRI. When no lesion is found the patient must be followed up, and imaging should be repeated at least once. Neurology evolves with the lessons of history to better modern practice; the lesson of Raeder is learnt and requires more transparent dissemination, including dropping the eponym. One might simply argue that to learn one thing - that is, the paratrigeminal oculosympathetic syndrome-is to learn the entire lesson, to learn a person's name adds nothing more in clinical terms. The use of such eponyms remains, however, a matter of taste and practice; and for Raeder should be tightly coupled to the anatomy.

\section{ACKNOWLEDGEMENTS}

I thank Dr Peter Drummond for helpful comments on the manuscript. PJG is a Wellcome Trust senior research fellow.

\section{REFERENCES}

1 Raeder JG. "Paratrigeminal" paralysis of the oculo-pupillary sympathetic. Brain 1924;47:149-58.

2 Mokri B. Raeder's paratrigeminal neuralgia. Original concept and subsequent deviations. Arch Neurol 1982;39:395-9.

3 Vijayan N, Watson C. Raeder's syndrome, pericarotid syndrome and carotidynia. In: Rose FC, ed. Headache. Handbook of clinical neurology. Vol 48. Amsterdam: Elsevier, BV, 1986:329-41.

4 Solomon S, Lustig P. Benign Raeder's syndrome is probably a manifestation of carotid artery disease. Cephalalgia 2000;20:in press.

5 Drummond PD. Dysfunction of the sympathetic nervous system in cluster headache. Cephalalgia 1988;8:181-6.

6 Drummond PD. Autonomic disturbance in cluster headache. Brain 1988;111:1199-209.

7 Warwick R, Williams PL. Gray's anatomy. 35th ed. Edinburgh: Longman Group Ltd, 1973.

8 Drummond PD, Lance JW. Pathological sweating and flushing accompanying the trigeminal lacrimation reflex in patients with cluster headache and in patients with a confirmed site of cervical sympathetic deficit. Evidence for parasympathetic cross-innervation. Brain 1992;115:1429-45.

9 Drummond PD, Lance JW. Facial flushing and sweating mediated by a sympathetic nervous system. Brain 1987;110:793-803.

10 Flett DL, Bell C. Topography of functional sub-populations of neurons in the superior cervical ganglion of the rat. J Anat 1991;177:55-66.

11 Wilson WC. Observations relating to the innervation of sweat glands to the face. Clin Sci 1936;2:273-86.

12 May A, Goadsby PJ. The trigeminovascular system in humans: pathophysiological implications for primary headache syndromes of the neural influences on the cerebral circulation. J Cereb Blood Flow Metab 1999; 19:115-27. 


\section{CORRESPONDENCE}

\section{Apomorphine as an alternative to sildenafil in Parkinson's disease}

I was interested in the recent paper by Hussain et al describing the efficacy of sildenafil citrate for erectile dysfunction in patients with Parkinson's disease or multiple system atrophy (MSA). Their findings provide reassurance that this popular drug is both effective and safe in parkinsonian patients provided orthostatic hypotension is recognised as a potentia side effect in MSA. Sildenafil inhibits cyclic GMP specific phosphodiesterase thereby enhancing nitric oxide mediated relaxation of the corpus cavernosum. The authors do not mention any effects of sildenafil on parkinsonian symptoms, although its mechanism of action would make this unlikely.

In addition to erectile dysfunction, many factors including motor symptoms contribute to sexual dysfunction and dissatisfaction in this population. I have previously reported penile erections in a significant proportion of patients following subcutaneous injections of the dopamine agonist apomorphine to treat motor fluctuations in Parkinson's disease. Some of these patients started using intermittent apomorphine injections specifically for erectile dysfunction. In contrast to sildenafil dopamine agonists act centrally on dopamine receptors in the paraventricular nucleus of the hypothalamus to stimulate oxytocin release. The benefit to motor symptoms in Parkinson's disease is mediated through dopamine receptors in the striatum. Apomorphine also benefits motor disabilities in some patients with MSA although orthostatic hypotension may be exacerbated by stimulation of peripheral dopamine receptors and its role in erectile dysfunction in this group has not been explored.

In view of the additional benefits to parkinsonian motor symptoms, subcutaneous apomorphine should be regarded as an alternative to sildenafil in treating patients with Parkinson's disease and erectile dysfunction. Sublingual preparations of apomorphine have recently been developed for this indication.

J D O'Sullivan

Department of Neurology, Level 7, Ned Hanlon Building, Royal Brisbane Hospital, Herston Road, Herston, QLD 4121, Australia

\section{References}

1 Hussain IF, Brady CM, Swinn M, et al. Treatment of erectile dysfunction with sildenafil citrate (Viagra) in parkinsonism due to Parkinson's disease or multiple system atrophy with observations on orthostatic hypotension. $J$ Neurol Neurosurg Psychiatry 2001;71:371-4.

2 O'Sullivan JD, Hughes AJ.

Apomorphine-induced penile erections in Parkinson's disease. Mov Disord 1998;13:536-9

3 Argiolas A, Melis MR, Mauri A, et al. Paraventricular nucleus lesion prevents yawning and penile erection induced by apomorphine and oxytocin but not by ACTH in rats. Brain Res 1987;421:349-52.

4 Dula E, Bukofzer S, Perdok R, et al. Double-blind, crossover comparison of $3 \mathrm{mg}$ apomorphine SL with placebo and with $4 \mathrm{mg}$ apomorphine $\mathrm{SL}$ in male erectile dysfunction. Eur Urol 2001;39:558-3.

\section{Conflict of intentions or inner negativism?}

In a recent, fascinating article, Nishikawa et al $^{1}$ describe their encounter with "three patients with callosal lesions who sometimes could not perform whole body actions as they intended because another intention emerged in competition with the original one." Believing that "no specific term has yet been coined for this symptom," they "tentatively" named it "conflict of intentions."

In fact, however, this symptom was described by Bleuler in his Textbook of psychiatry, which first appeared in English translation in 1924. Bleuler termed it "inner negativism," and noted that when "patients make an effort to start an action ... a counter-impulse, or only a mere blocking appears and hinders them in its execution." Such inner negativism could prevent "the simplest acts like eating. The spoon is arrested half way up to the mouth and must finally be put down again."

The great service of Nishikawa et al is to demonstrate the localising value of this symptom to the corpus callosum; it would be a disservice to medical history, however, to rename it.

D P Moore

Department of Psychiatry and Behavioural Sciences, University of Louisville School of Medicine, c/o Central Hospital, La Grange Road, Louisville, KT 40223,USA; dpmooremd@cs.com

\section{References}

Nishikawa T, Okuda J, Mizuta I, et al. Conflict of intentions due to callosal disconnection. I Neurol Neurosurg Psychiatry 2001;71:462-71.

2 Bleuler E. Textbook of psychiatry. (Translated by AA Brill.) New York: Arno Press, 1976:154, 407

\section{Author's reply}

We are very grateful for Dr Moore's interest and comments on our article. We believe that the value of our study lies, firstly, in having rediscovered the significance of a symptom in some cases of partial callosal disconnection The literature has been largely silent about this except for a few episodic descriptions in case reports. Secondly, we link it to the so called callosal disconnection syndromes by clarifying its clinical features and discussing possible pathogenic mechanisms. We gave the symptom a new label- “conflict of intentions" - because it differs from any other callosal symptoms and cannot be explained by established disconnection theories, given that this symptom manifests itself without being confined to one half of the body.

Dr Moore comments that the symptom we reported has already been described in Eugen Bleuler's classic textbook and termed "inner negativism" ("innerer Negativismus" in the original). He asserts that assigning new terminology to an essentially identical symptom would be a disservice to medical history. We disagree.

We consider that the terminology used in descriptive symptomatological studies is conceptually different from that used in studies that take into account both phenomenology and pathogenesis. In Bleuler's textbook, "inner negativism" appeared in the chapters about general descriptive symptomatology and schizophrenia. Our "conflict of intentions", on the other hand, is a purely neuropsychological term meant to denote a particular type of callosal disconnection syndrome. We hypothesise links between psychopathological phenomena and underlying pathogenic neural mechanisms. In other words, we do not intend to equate the neuropsychological term "conflict of intentions" with the purely descriptive term "inner negativism."

We agree that the symptom described by Bleuler has much in common with that seen in our patients. Indeed, we hope that our speculations about the conflict of intentions will help to elucidate the neural mechanisms of some well known psychiatric symptoms such as ego disturbances in schizophrenia and ego dystonic experiences in obsessive compulsive disorders. In the future, these symptoms may be explained in terms of the dynamics among intentional, responsive, and automatic factors in behaviour, or among their respective main neural substrates - that is, the left and right cerebral hemispheres and lower neural systems-which we assume to be elements for explaining general human behaviour. Until such a unifying theory is established, we think it may not be such a disservice to medical history to preserve a distinction between the developmental processes of descriptive psychiatry and neuropsychology by retaining both terms, Bleuler's "inner negativism" and our "conflict of intentions".

T Nishikawa, I Mizuta, M Takeda

Department of Clinical Neuroscience and Psychiatry, Osaka University Graduate School of Medicine, Osaka, Japan

J Okuda

Department of Psychiatry, Shoraiso National Hospital, Nara, Japan

Correspondence to: Dr Nishikawa, Department of Clinical Neuroscience and Psychiatry, Osaka University Graduate School of Medicine, D3, 2-2 Yamadaoka, Suita City, Osaka 565-0871, Japan; nisikawa@psy.med.osaka-u.ac.jp

\section{BOOK REVIEWS}

Practical psychiatry of old age, 3rd edn

Edited by J P Wattis, S Curran (Pp 268 $£ 24.95)$. Published by Radcliffe Medical Press Ltd, Abingdon, 2001. ISBN 1857752457

It is a curious thing that old age psychiatry is such a geographically weak discipline. There are many and excellent old age psychiatrists in Australia and Norway. The UK is arguably the home of old age psychiatry and the discipline is well established in the United States. However, in most European countries, let alone further afield, old age psychiatry as a discipline either doesn't exist or is limited in scope.

This is a shame, as amply shown by this book. The argument in favour of old age psychiatry is well presented by Wattis and Curran. It is discipline that is at home with physical disease as much as what used to be called functional disorders; a discipline that is perhaps the most comfortable with multidisciplinary working; a discipline that can move in the course of a day's clinical work from molecular genetics to psychotherapy with 
demented people. Practical psychiatry of old age, now in its 3rd edition, brings together the many fields of our discipline. It is liberally scattered with useful and interesting case histories and the advice on management is sensible and up to date.

The book is clearly written for a trainee and non-specialist audience and deals with most subjects with a fairly light touch. The references at the end of the chapters serve as useful reading lists, including as they do both recent and historical papers. For students and for trainees this book will provide a useful revision and summary aid although trainees will need also to have to hand some of the weightier texts. Those in other disciplines may well find the book helpful to understand some of the classification and nomenclature issues of old age psychiatry.

Like the discipline itself, however, this book is very much a British affair. The sections on services have only limited international relevance and even the concept of a doctor who manages late onset psychosis, personality disorder, depression, and dementia is not so common elsewhere. The concentration on the international classification of diseases has limited application in the United States. So for those in the UK who need an introductory text to this best of medical disciplines, this book is a sensible choice. To those who have yet to appreciate the joys of being an old age psychiatrist, dip into a colleague's copy-you may be pleasantly surprised.

Simon Lovestone

\section{Brain Imaging in Schizophrenia, Insights and Applications}

Edited by T Sharma, X Chitnis (Pp 74, $£ 12.50)$. Remedica Publishing, London, 2000. ISBN 1901346080

This is a succinct overview of brain imaging studies in schizophrenia and is well illustrated with scan photographs. The first two chapters cover the techniques of brain imaging and include several tables summarising information. The structural imaging chapter describes the techniques of computed tomography and MRI, and introduces the novel methods of diffusion weighted imaging and magnetisation transfer imaging. Complex topics such as the underlying principals of MRI are tackled in a fairly accessible manner. The functional brain imaging chapter covers PET SPECT, fMRI, and MRS. The next two chapters cover the results of structural and functional imaging studies. These chapters are thoughtfully subdivided, and papers up to and including the year 2000 are cited. The brevity of the volume of course restricts the range of studies discussed, but generally the selection is good. Space also prevents areas of conflict from being fully resolved, for example into differing scan methodologies, data analysis protocols, and clinical populations. The penultimate chapter is titled "Genetics and brain imaging," and describes imaging studies in twin pairs and members of multiply affected families. It includes discussion of the subtle abnormalities identified in presumed carriers. Finally there is a brief concluding chapter examining the current and future applications of the various imaging techniques in the study of schizophrenia. Overall, the results presented confirm that the complexity and heterogeneity of schizophrenia makes a simple uniform underlying pathology seem unlikely. Imaging studies, with their unique ability to examine the brains of living patients, have an important role in developing our increasingly sophisticated understanding of the disorder. I would recom- mend this well written monograph both to academics and to clinicians wishing to keep up with this fascinating and fast evolving area.

\section{R Alexander Bantick}

\section{Parkinson's Disease in the Older Patient}

Edited by J R Playfer, J V Hindle (Pp 370, $£ 55.00)$. Arnold, London, 2001. ISBN 0340759143

This is a welcome addition to the literature. The book has been published with the help and support of the British Geriatrics Society special interest group in Parkinson's disease and the Parkinson's Disease Society of the United Kingdom. Both organisations have been at the forefront of increasing public and professional awareness of the need for a holistic approach to the care of older people with this condition. Understanding of the pathophysiology, therapeutics, and progression of the disease, as well as the introduction of Parkinson's disease nurses and specialist clinics have all led to significant improvements in patients' quality of life. This well referenced publication will add to the knowledge base of neurologists and geriatricians in practice as well as in training.

There are 21 chapters, in five parts, which address topics ranging from the historical background of Parkinson's disease to its diagnosis and assessment, written by Drs Macphee, Meara, and Forsyth. In the absence of a foolproof test for Parkinson's disease, these chapters go a long way to reminding readers of the importance of history, examination, assessment, and therapeutic challenge. The remaining parts include specific problems in Parkinson's disease, therapy and management, and research perspectives.

The chapter by Dr MacMahon on the organisation of services, concepts of management, and health economics builds on his theory of effective management of chronic disease, emphasising the importance of staging Parkinson's disease in terms of diagnosis, maintenance, and complex and palliative care. His paradigm for Parkinson's disease disease management is used by many geriatricians and is described it in greater detail for the benefit of a wider audience of clinicians.

There are also interesting chapters on rehabilitation and the interdisciplinary team, the Parkinson's disease nurse specialist, complementary and alternative medicine, and of course drug treatment by Dr Playfer, one of the editors. The other editor, Dr Hindle, has written a beautifully argued chapter on the complexity of neuropsychiatry in this syndrome, and autonomic problems are eloquently described by Professor Kenny and Dr Allcock. Unfortunately it is impossible to acknowledge all the authors, but no aspect of Parkinson's disease is left unchallenged. The development of a properly managed, costeffective, and evidence based service is the underlying theme throughout the book.

Without a multidisciplinary holistic approach to the care of older people with Parkinson's disease, we will continue to offer inhumane, crisis driven care for these challenging patients and their carers. "Parkinson's Disease in the Older Patient" provides the knowledge base.

Jackie Morris

\section{Brain's diseases of the nervous system, 11 th edn}

Edited by M Donaghy (Pp 1242, £150.00). Published by Oxford University Press, Oxford, 2001. ISBN 0192626183

Lord Brain left us two neurological textbooks The smaller, Brain's clinical neurology, subse- quently revised by Sir Roger Bannister, is known affectionately as "Little Brain". Diseases of the nervous system, or "Big Brain", remained a single author work until the 9th edition. By then, it had passed into the hands of Lord Walton, who brought in 12 coauthors for the 10th edition. This 11th edition, completely revised under the new leadership of Michael Donaghy, has contributions from 14 authors, all working in British institutions.

The decision to continue with relatively few contributors, all from the same country, might have laid the book open to charges of being parochial or elitist. However, the result is a volume with a cohesive style where unnecessary overlap has largely been avoided and omissions are few.

Even nowadays, there is only a handful of standard neurology reference texts, so comparisons are inevitable, in particular with Neurology in clinical practice by Bradley et al. Brain's diseases has the signal advantage over Neurology in clinical practice of being contained within a single volume, albeit one large enough to disperse a ganglion more efficiently than any family Bible.

The arrangement of chapters in this edition of Brain's diseases is as logical as in any other major text-Lord Brain himself acknowledged in the first edition that there is no easy answer to this problem. After an introductory section, the book is effectively a series of monographs on diseases of the cranial and peripheral nerves and muscle, then structural disease of the neuraxis, followed by epilepsy, coma, and dementia. Finally, the major pathological processes are described: vascular, demyelinating, inflammatory, degenerative, and infective.

Generally, these topics are covered with great authority, wisdom, and scholarship. So criticism of this icon of British neurology may seem unchivalrous but here are some minor comments. Firstly, regarding style, in striving to avoid dryness the authors are occasionally unduly colloquial (“Nonsense!" p 85) or hectoring ("Whatever else, it is important for neurologists to ..." p 899).

As for content, there are a few lapses. In particular, discussion of the pathophysiology of symptoms and signs lacks depth: Hughlings Jackson would have baulked at the definition of positive symptoms given on p 13 . With a book of this size, there is bound to be some variation in quality and the chapter on vasculitis and collagen vascular disorders is weaker than the rest. Though these conditions are relatively rare, their management is important, as it frequently vexes neurologists. It is simply inadequate to dismiss their classification as unsatisfactory and end the brief discussion of this topic with the implication that they can all be lumped together anyway, as the treatment is usually immunosuppression. In the same section, lupus and the antiphospholipid syndrome are given as examples of the difficulty of accurate subclassification. But this is one situation where there are clear differences in treatment-that is, immunosuppression versus antiplatelet therapy and/or anticoagulation. Later in the same chapter, eosinophilia is given as a feature of Wegener's granulomatosis yet is mysteriously omitted from the adjacent paragraph on ChurgStrauss syndrome.

Consistent nomenclature is always a concern in large multiauthored texts. Here, there are predictable difficulties with the hereditary neuropathies and with what to call idiopathic brachial plexopathy - the author plumping for the rather antiquated "acute brachial neuritis". It is a pity that the one disease for which the British can claim special expertise-the human 
form of bovine spongiform encephalopathygoes under two names, "variant CreutzfeldtJakob disease" in the section on dementia and "new variant Creutzfeldt-Jakob disease" in that on infection.

Finally, there are typographical errors, which are too many for comfort, especially in the tables, figures, and references, giving the impression that the book was rushed in its final production stages. Perhaps the most alarming was the discovery of a new cranial nerve, the 13th, in table 1.4. Figure 8.5 shows a retinal hamartoma, not haematoma. Figure 8.4 shows the optic fundus at an unusual angle. Figure 11.9 is anatomically incorrect. Figures 7.3 and 29.11 are too small. The caption to figure 2.23 is incomprehensible Many other examples could be given.

But these are mainly minor quibbles, easily rectified when the book is reprinted. Taken as a whole, Big Brain is alive and well, and safe in the hands of its new editor and his coauthors.

Lionel Ginsberg

\section{Textbook of Clinical Neuropsychiatry}

Edited by D P Moore (Pp 747, £69.50). Arnold, London, 2001. ISBN 0340806249

There is a certain logic to the system Moore uses in his textbook of clinical neuropsychiatry. The first half of the book essentially consists of numerous lists of causes of different symptoms, signs, and syndromes. For example lists are provided for causes of dementia lacking distinctive features, dementia associated with strokes, and dementia with frontal lobe syndrome or with parkinsonism. Confronted with a patient with dementia plus parkinsonism the reader has quick access to conditions that need to be considered. Or if the reader is looking for a list of causes of catatonia he need look no further than table 3.8. Having identified the potential causes of the patient's symptoms the reader then goes to the second half of the book where he will find up to date descriptions of the relevant neuropsychiatric diagnoses.

The problem with such an approach is that it leads to duplication. In the first half any single diagnosis has to appear as many times as there are symptoms, signs, or syndromes that it can produce. The approach depends heavily on the validity of the classification of symptoms and syndromes; conditions with different names often seem to share more in common than sets them apart. For example it is asserted that stupor can be distinguished from akinetic mutism partly on the basis of eye movements: in the former they are generally roving or dysconjugate, whereas in akinetic mutism lively conjugate tracking eye movements are to be seen. I am not so sure and would have preferred a critical discussion of the nosological status of akinetic mutism alongside abulia, stupor, and catatonia. Frontal lobe syndrome is given syndrome status, but I could find no mention in the book on the dysexecutive syndrome.

What is lacking in this book is a sense of proportion. Three of the biggest suppliers of referrals to a neuropsychiatric service-stroke, head injury, and conversion disorders-hardly get a mention. Given the huge range of conditions that are covered it is not surprising that the book sometimes gives a sense of having been written in the library rather than from clinical experience. But there are some excellent sections; I was particularly impressed by the chapters on epilepsy and the introduction to EEG.
It is a very comprehensive textbook. This is its strength. The complete range of neuropsychiatric conditions is described in a consistent, easy to read, format. Large numbers of up to date references are provided.

Overall Dr Moore is to be congratulated on producing a useful textbook. Two neuropsychiatric colleagues gave this book the thumbs up because Moore has achieved his aim of offering this book as a ready reference for established practitioners. It will be of interest to both neurologists and psychiatrists.

Simon Fleminger

\section{Wolff's Headache and Other Head Pain, 7th edn.}

Edited by S D Silberstein, R B Lipton, D J Dalessio (Pp 625, US\$99.00). Oxford University Press, Oxford, 2001. ISBN 0195135180

There can be few people still alive who came under the direct influence of Harold G Wolff before his death in 1962 (Donald Dalessio being one), but his influence on the whole of neurology has been immense and still continues. His book soon became a classic - the two editions he wrote himself are now acquired only with difficulty from antiquarian booksellers. Over the years it has become slowly transformed, though perhaps some intermediate editions were a less satisfactory hybrid between the master and later developments. "Wolff's Headache" has now emerged as a fully fledged multiauthor text in its own right, with less emphasis on the master's own experimental work. We now have a 600 page authoritative book, written largely by American authors, all clearly experienced clinicians. It is comprehensive and yet more manageable than its main competitors.

In the first 100 pages the classification, anatomy, pathophysiology, genetics, and epidemiology of headache are covered, with discussion of imaging techniques and comorbidity with other diseases. The core of the book covers migraine, cluster headaches, and tension headaches, including a very comprehensive review of every drug that has ever been used to treat headache, including the obscure, the ineffective, and the promising. This section is also strong on the classification of chronic headache syndromes and in discussing analgesic abuse. The third section discusses every conceivable structural cause of headache, including high and low CSF pressure, metabolic disease, and disorders of the neck, eyes, teeth, nose, and blood vessels, including all the classic citations. The final three chapters discuss headache in children, behavioural management, and the consultation process itself.

This is an outstanding book; little of significance is omitted, and yet one is not overwhelmed with details. No doubt with the trainee entering the field in mind, it is particularly good when reviewing the literature, though some authors do occasionally lapse into uncritical catalogues of older papers. It will prove to be a useful reference text for more senior neurologists confronted with a difficult patient, both for diagnostic and therapeutic options, though these are perhaps more from an American viewpoint.

Richard Peatfield

\section{Multiple sclerosis: tissue destruction and repair}

Edited by L Kappos, K Johnson, J Kesselring, and E W Radu (Pp 350, £65.00). Published by Martin Dunitz Ltd, London, 2001. ISBN 1 853178721

The Martin Dunitz imprint produces high quality books with catchy titles often built around European congresses of neurology. Brain disease: therapeutic strategies and repair emerged from the European Neurology Society meeting in Jerusalem (2000). Multiple sclerosis: tissue destruction and repair is the proceedings of the joint meeting of ECTRIMS and ACTRIMS (European and American Committees for Treatment and Research in Multiple Sclerosis) held in Basel in 1999. Looked at critically, neither book is much about repair. Here, the 116 contributors to 37 chapters edited by a team from Switzerland and Baltimore write on central nervous system-tissueimmune interactions; in vivo assessment of tissue destruction and its consequences; multiple sclerosis fatigue; new immunological concepts and their therapeutic consequences; treatment of relapse; modern concepts of therapeutic immunosuppression; and an update on therapeutic trials. Many of the usual suspects are rounded up: magnetic resonance surrogates for various histological components of the disease process in multiple sclerosis; markers of demyelination in body fluids; treatment effects of interferon beta and its mechanisms of action; and strategies for transplantation in multiple sclerosis. Some authors rake up old matters: the use of steroids in acute episodes; and disease modifying effects of non-specific immunosuppressants. But there are also some new or emerging stories: inflammation and neuronal activity; interactions between inflammatory mediators and growth promoting molecules; fMRI evidence for plasticity in multiple sclerosis; $\mathrm{T}$ helper and $\mathrm{T}$ regulatory activity; bone marrow transplantation in multiple sclerosis; prophylactic treatment of puerperal disease activity with intravenous immunoglobulin; and a brace of preliminary clinical trials with hitherto unknown agents offering spaces to watch. Multiple sclerosis: tissue destruction and repair succeeds as a statement from experts on where selected aspects of research stood in 1999 and as testimony to the deserved and sustained success of ECTRIMS (and ACTRIMS) but as a lasting statement on limiting and repairing the damage in multiple sclerosis, perhaps less so.

Katrina Dedman

\section{Current management in child neurology, 2nd edn}

Edited by Bernard L Maria (Pp 562, US\$74.95). Published by BC Decker Inc, Hamilton, 2002. ISBN 155009162X

Management includes assessment, diagnosis, and treatment. What emerges therefore is a book of clinical paediatric neurology - not a book on treatment in paediatric neurology. It is divided into outpatient and inpatient conditions and priority within these areas is apportioned by incidence. The top four outpatient neurological conditions presenting to paediatricians in Florida are attention deficit hyperactivity disorder (ADHD), seizures and epilepsy, developmental delay, and headache. The top four discharge diagnoses from hospital on the other hand are enteroviral meningitis, epilepsy, hyperkinetic syndrome (which the author explains by the presence of comorbid conditions requiring hospital treatment), and concussion.

The aim of this book is to provide "primary care physicians, neurologists and house staff with factual information on how to treat children with the most common disorders of the nervous system".

There are some surprising omissions including spinal dysraphism. Movement disorders generally get short shrift. Of the 550 
pages, cerebral palsy gets five (biomechanics gets five lines, prevention of secondary deformity is ignored), although there are a further eight on spasticity. There is nothing on chorea or dystonic syndromes-the latter omission is particularly surprising in view of the treatment implications.

In these days of economic scrutiny the evidence base for treatment recommendations should be referenced but is not for cerebral palsy, language disorders, or learning disability.

One hundred and nine authors contributed to this book. That so many have been induced to contribute may be because few provide more than seven pages. Thus, the most extensively treated topic is that of epilepsy with 86 pages from 13 separate authors. This leads to redundancy (treatment with antiepileptic drugs in most chapters but especially those on first choice antiepileptic drugs and recurrent seizures) and surprising omissions. A diagnostic approach to Lennox-Gastaut syndrome and progressive myoclonic epilepsies would have been useful. Nowhere are the implications of the genetics of familial epilepsies described. Genetic counselling generally is mentioned only in the chapters on neurofibromatosis and tuberous sclerosis. The concept of channelopathies is absent throughout.

The target audience for this book see a lot of headaches; hence, 46 pages and seven authors. Again, redundancy and gaps. No one mentions taking the blood pressure of a child with headache. Neuroimaging is thought unnecessary unless there are abnorma neurological signs. A slightly more sensible discussion is found on page 491 in the inpatient chapter dealing with acute headache.

Prominent also is ADHD with 26 pages and five authors, reflecting the American referral patterns described above. Another curious (to the European paediatric neurologist) area of practice is outlined in the chapter "Is my child ready for school?" (by which is meant for normal school since all American children are entitled to education). At the end of four pages, which include a list 14 tests - seven of which require special training and at least five of which seem specifically designed to address the question-it is concluded that "the paediatrician or family physician can assess school readiness using a thorough, careful medical history and physical examination"!

In contrast there are five pages on inborn areas of metabolism and eight on neurodegenerative disorders. Both tend to give lists of conditions but not the screening tests including DNA analysis for those conditions. Statements such as the value of increased cerebrospinal fluid lactate are of limited value unless normal concentrations are given. Curiously phenylketonuria is not mentioned. Half a page is given to treatment of inborn errors Enzyme replacement is not mentioned under the neurodegenerative conditions. While these conditions are individually rare, their collective burden is considerable. Many, particularly the inborn errors, are both treatable and susceptible to prenatal diagnosis. Similar comments may be made for the hereditary neuropathies (eight pages) and muscular dystrophies and myopathies (eight pages). Muscle histology gets five lines.

Some omissions may be considered dangerous. Meningoencephalitis is not mentioned as a cause of neonatal fits, optic neuritis as a cause of visual loss, and dystrophia myotonica as a cause of neonatal hypotonia. Step 2 in the treatment of status epilepticus is to give fosphenytoin. But what if the child is already on phenytoin? Step 3 has the child on either a midazolam or a pentobarbitone infusion achieving burst suppression pattern on electroencephalography-but no advice is provided on what to do if either of these drugs fails or, if they succeed, what to do next.

No doubt there are areas the American physician will find useful-particularly, for example, the chapters on the economics of the health care system in the United States and advice on practice business management. Nevertheless, I think that this book sits uneasily between the needs of the general paediatrician and the needs of the neurologist. For the former there is more information-or not enough in a useable form-than is useful and for the latter the text is just not up to the standard already provided elsewhere. With the book is provided a CD-ROM, which has the text plus links to child neurology websites and the National Library of Medicine. Those who purchase this book are advised to avail themselves fully of these facilities.

Richard O Robinson

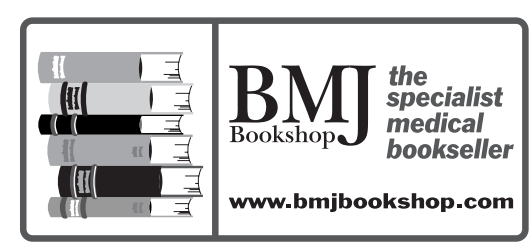

\section{CORRECTIONS}

J Stone, M Sharpe, G Elrington. Amnesia for childhood in patients with unexplained neurological symptoms. J Neurol Neurosurg Psychiatry 2002;72:416-17. During the production process G Elrington's name was omitted. The author list should read as shown.

PJ Goadsby. Paratrigeminal paralysis of oculopupillary sympathetic system. J Neurol Neurosurg Psychiatry 2002;72:297-9. During the production process the title was inadvertently shortened. The title should read: Raeder's syndrome: paratrigeminal paralysis of oculopupillary sympathetic system. 